\title{
RESEARCH
}

Open Access

\section{Effectiveness of a low-value financial- incentive program for increasing vegetable- rich restaurant meal selection and reducing socioeconomic inequality: a cluster crossover trial}

\author{
Wataru Nagatomo', Junko Saito ${ }^{1,2}$ and Naoki Kondo ${ }^{1 *}$ (D)
}

\begin{abstract}
Background: In light of recent theories in behavioural economics, an intervention program with monetary incentives could be effective for helping patrons order healthy food, even if the incentive is small and less than one's perceived marginal value.

Methods: In this single-arm cluster crossover trial at 26 local restaurants, a 1-week campaign offered a 50-yen (approximately 0.5 US dollars) cash-back payment to customers ordering vegetable-rich meals, while no pre-order incentives were offered during the control period.

Results: In total, 511 respondents out of 7537 customers (6.8\%), and 704 respondents out of 7826 customers (9.0\%), ordered vegetable-rich meals during the control and intervention periods, respectively. During the intervention period, the covariate-adjusted proportion of vegetable-rich meal orders was 1.50 times higher (95\% confidence interval [Cl]: 1.29 to 1.75 ), which increased daily sales by 1.77 times (95\% Cl: 1.11 to 2.83), even when subtracting the cost of cash-back payments. Respondents who reported spending the least amount of money on eating out (used as a proxy measure for income) were the least likely to order vegetable-rich meals during the control period. However, these individuals increased their proportion of purchasing such meals during the intervention period (a 3.8 percentage point increase (95\% Cl: 2.82 to 4.76 ) among those spending the least vs a 2.1 percentage point increase (95\% Cl: 1.66 to 2.62) among those spending the most; $P$ for interaction $=0.001)$. Similarly, irregular employees exhibited a larger increase $(+5.2$ percentage points, $95 \%$ Cl: 4.54 to 5.76$)$ than did regular workers $(-1.4,95 \% \mathrm{Cl}:-1.66$ to $-1.05, P$ for interaction $=0.001)$.
\end{abstract}

Conclusions: A program with an immediate low-value monetary incentive could be a public health measure for reducing inequalities in making healthy food choices.

Trial registration: UMIN Clinical Trials Registry, UMIN000022396. Registered 21 May 2016.

Keywords: Health inequality, Diet, Health behaviour, Marketing, Nudge, Japan

\footnotetext{
* Correspondence: naoki-kondo@umin.ac.jp

${ }^{1}$ Department of Health Education and Health Sociology, School of Public Health, The University of Tokyo, 7-3-1 Hongo, Bunkyo-ku, Tokyo 113-0033, Japan

Full list of author information is available at the end of the article
}

(c) The Author(s). 2019 Open Access This article is distributed under the terms of the Creative Commons Attribution 4.0 International License (http://creativecommons.org/licenses/by/4.0/), which permits unrestricted use, distribution, and reproduction in any medium, provided you give appropriate credit to the original author(s) and the source, provide a link to the Creative Commons license, and indicate if changes were made. The Creative Commons Public Domain Dedication waiver (http://creativecommons.org/publicdomain/zero/1.0/) applies to the data made available in this article, unless otherwise stated. 


\section{Background}

Non-communicable diseases (NCDs) constitute a global health issue, accounting for two-thirds of deaths worldwide [1, 2]. In many countries, NCD-related deaths and their behavioural risks, such as smoking, drinking, and insufficient intake of vegetables and fruit, are more frequent among people with low socioeconomic status (SES) compared to those with high SES [3-9]. Given that individual SES is largely attributable to structural factors in society, national policies for providing financial protections, including income redistribution measures and universal healthcare coverage, are essential [10-12]. Nonetheless, health gaps clearly exist, even in countries offering the most affordable welfare services [1]. Alternative approaches to promote healthy behaviours are needed. Such interventions should be evaluated for their effectiveness among socially disadvantaged groups [2, 3], but the evidence is still limited.

In recent years, much attention has been paid to the notion of encouraging people to make favourable choices while safeguarding the individual's discretion to make his or her own decisions [13-15]. Price changes of unhealthy and healthy goods and services (e.g. tobacco and sugar-sweetened beverages) is a popular and effective measure [16-18]. As people with lower incomes tend to focus on prices when choosing foods, price changes could be a useful public health measure for reducing socioeconomic inequality in regards to behaviour choices [19-21]. However, existing research has mainly evaluated the efficacy of such measures in a laboratory environment $[22,23]$, and few studies have evaluated the effectiveness of positive monetary incentives for reducing socioeconomic inequality regarding healthy food choices in real-world settings [24]. Importantly, price change interventions could be effective, even though the difference between new and old prices may not be sufficient to fully overcome the difference in utility to consumers. For example, although the size of a discount may not be in line with consumers' actual willingness to pay for the $\operatorname{good}(\mathrm{s})$ in question, individuals may still purchase the item(s), due to biases in human cognition and behaviour, including framing effects and loss aversion [25]. Therefore, we conducted an intervention study, within a real-world setting, whereby a "small cash back" measure was implemented to encourage people to select vegetable-rich meals from menus at participating restaurants. We tested three hypotheses: (1) the intervention will increase overall vegetable-rich meal orders; (2) restaurants' total sales will increase; and most importantly, (3) vegetable-rich menu orders will increase in proportion to the individual's level of social disadvantage.

\section{Methods}

\section{Research setting and design}

The government of Adachi Ward, a business and residential area in the northern Tokyo metropolitan area, runs a program entitled "Eat Vegetables Daily" (in Japanese: Adachi beji-tabe-raifu). The program was put in place as part of a set of type 2 diabetes countermeasures [26-29] strengthening environmental interventions for the communities, rather than providing health educational opportunities for individuals [26, 27]. With this program, the government has sought collaborations with nearly 600 local restaurants and retail shops. Within these locales, "vegetable-rich" meals are served. For a shop or restaurant to be certified as a partner, it must develop and serve vegetable-rich meals containing at least $120 \mathrm{~g}$ or more of vegetables per serving (except potatoes). In June 2016, we conducted a single-arm cluster crossover trial at local restaurants. The inclusion criteria were that the restaurant was already participating in the program and that the restaurant accepted an invitation from the Adachi government to participate in this study. We obtained informed consent, asking customers not to answer the questionnaire if they were not willing to participate in the study. We excluded those who were unable to communicate in Japanese or read the survey's participation agreement form.

Two continuous weeks were designated as the data collection period: the first week was the control period, and the second week was the intervention period. We allocated each cluster, a restaurant, to both the control and intervention periods. During the intervention period, we implemented a cash-back campaign in which 50 yen were refunded upon payment to any customer ordering a vegetable-rich meal (a US dollar equalled 105.49 yen in June 2016 [30]). During the intervention period, the participating restaurants displayed posters informing customers that the campaign was underway and placed vegetable-rich menus in front of their entrances so that customers could sufficiently account for the incentives provided by the campaign before ordering. To prevent the restaurant owners from displaying the poster before the intervention period, we sent an advertising poster to be displayed in the front of the restaurant a few days before the intervention period. We also provided oral and written guidance, requesting that restaurant owners display the poster on the morning of the first day of the campaign and to avoid displaying it during the precampaign period.

To maximise data accuracy, feasibility, and practicality in a real-world setting, we did not conduct a parallelgroup randomised trial. Compared to a simple cluster randomised trial, a single-arm crossover design has the advantage of completely matching the restaurants' characteristics between the control and intervention periods. 
The Research Ethics Committee of the Faculty of Medicine at the University of Tokyo (UMIN Clinical Trials Registry number: UMIN000022396) approved this protocol.

\section{Data collection}

During the control and intervention periods, we conducted surveys using self-administered questionnaires, with two different sets of targets and protocols. During the intervention period, a 50-yen cash-back incentive was offered for ordering a vegetable-rich meal, but this payment was conditional on submitting a completed questionnaire sheet. To collect information on individuals who ordered vegetable-rich meals, the first survey targeted all customers who ordered such meals during both the control and the intervention periods (survey $\mathrm{A}$ ). For survey A, we trained restaurant staff members on how to conduct all survey procedures, including distributing and gathering questionnaires and paying out the cash-back incentive. To avoid imbalances in questionnaire response rates between the intervention and control periods, we also offered cash back to those who ordered vegetable-rich meals during the control period. However, during the control period, information regarding the cash-back incentive was not provided to customers until they had decided on their order; thus, this information was provided after the order was placed.

To acquire data on the total number of customers based on SES, we conducted another survey targeting all customers, including those who did not order vegetablerich meals (survey B). We surveyed customers who visited during a randomly selected one-hour period during both the control and intervention periods at each restaurant.

We also asked the restaurant owners to provide information regarding their daily sales. Because meal selection was expected to be influenced by the weather, we also gathered daily weather information from the Japan Meteorological Agency website [31].

\section{Measurements}

\section{Restaurant sales data}

Restaurant owners provided information on the prices of vegetable-rich meals and other meals offered, as well as the number of visitors and total sales per day.

\section{SES}

Our SES indicators were educational attainment, employment status, and average daily expenditures on lunchtime eating as a proxy for income or purchasing power. To measure educational attainment, we asked participants to state their highest level of education completed, categorised as follows: high school or lower, vocational/technical school or junior college, or 4-year college/university or higher. We classified participants' employment status into four categories: regular employee, irregular employee, self-employed, and unemployed. To establish participants' daily expenditures on lunchtime eating, we asked: "Which price range do you use for eating out or buying food for lunch on average? Please exclude occasions when you bring your lunch from home" and categorised responses into three groups: 450 yen or less, $451-850$ yen, or 851 yen or more.

\section{Covariates}

Age, gender, day (weekday vs weekend), time surveyed, medical history, residence type, number of visits to the same restaurant during the same week, main objective of the visit, number of people in the respondent's party, whether or not the participant was familiar with the Adachi "Eat vegetables daily" program, usual type of lunch, health consciousness about food, interest in eating vegetables, and daily weather data were compiled as potential covariates.

\section{Sample size estimation}

Based on preliminary interviews with restaurant staff, we assumed that the proportion of vegetable meal orders would be $15 \%$ during the control period and $25 \%$ during the intervention period. Based on this assumption, we calculated that a sample of 247 site-days per period would provide $80 \%$ power to detect a difference of at least 10 percentage points at a $5 \%$ significance threshold.

\section{Statistical analyses}

After examining the restaurants' characteristics and balance of customers with different characteristics between the control and intervention periods, we conducted three analyses. First, we calculated the covariate-adjusted difference and ratio regarding the proportion of vegetable-rich meal orders during the intervention period compared to the control period. Subsequently, to calculate the incidence ratio of vegetable-rich meal orders between the two data collection periods, we used a Poisson regression model with a log link function and robust standard error estimation for the data of a single business day as the unit of analysis [32]. When calculating daily sales, we subtracted the cost of cash-back payments from the restaurant's total sales. We constructed a linear regression model using the log-transformed total sales with cash-back costs subtracted as the dependent variable and a dummy variable representing the intervention vs the control period as an explanatory variable. We estimated the ratio of and difference between the total sales and calculated the marginal means (i.e. the predicted values adjusted for the covariates mentioned above). Finally, we estimated the covariate-adjusted proportion of vegetable-rich meal orders according to 
individual characteristics and statistically evaluated between-SES differences in the difference between the two periods with the data at the individual level. We estimated denominator values, or the number of total daily customers, using the inverse of the sampling ratio from survey $B$ as the frequency weight in our regression models (i.e. the number of non-vegetable-rich meal orders during the 1-h sampling period/the total number of non-vegetable-rich meal orders in each period reported by the restaurants; Additional file 1: Supplementary Material 1). Because our preliminary analysis showed that the effect-size gaps across SES were not clearly linear, we categorised SES into multiple groups rather than using continuous variable specifications. An intentionto-treat approach was used for all analyses. All analyses were performed using STATA version 14.2 (STATA Corp LP., College Station, Texas, USA). Further descriptions regarding the methods are available in Additional file 1: Supplementary Material 2.

\section{Results}

The 26 participating restaurants (one dropped out) were diverse, including family and casual dining establishments, Izakaya (Japanese pubs), noodle shops, and those serving meals from various countries. The prices of vegetable-rich meals varied, ranging from 324 to 1450 yen (Table 1; Additional file 1: Supplementary Material 3). Among the 43 vegetable-rich meals served in participating restaurants, the price difference between the average vegetable-rich meal and the average regular meal was greater than 50 yen for 25 meals across 25 restaurants. The non-response rate for survey A (for all guests who ordered vegetable-rich meals) was $18.3 \%$ during the intervention period and $22.7 \%$ during the control period. The response rate for sampling survey B was $64 \%$ during the control period and $71 \%$ during the intervention period. In total, 511 respondents out of 7537 visitors (6.8\%), and 704 respondents out of 7826 visitors (9.0\%), ordered vegetable-rich meals during the control and intervention periods, respectively (Additional file 1: Supplementary Material 4 flow diagrams). The intraclass correlation coefficient was 0.112 (between-class variance: 0.007 , standard error [SE]: 0.003; within-class variance: 0.056 and $\mathrm{SE}: 0.112$ ). The average total sales per day were 73,157 yen during the control period (SE: 10,344 ) and 75,397 yen during the intervention period (SE: 11,078).

Compared to the control period, the crude proportion of vegetable-rich meal orders per day during the intervention period was 1.33 times higher (95\% confidence interval [CI]: 1.18 to 1.49 ; Table 2), and when covariates were adjusted, the value increased to 1.50 (95\% CI: 1.29 to 1.75 ). The crude total sales were also 1.14 times higher (95\% CI: 0.63 to 2.05), and when all covariates were adjusted, the value increased to 1.77 (95\% CI: 1.11 to 2.83), which was equivalent to an average daily revenue gain of 14,423 yen, even when subtracting the 50yen cash back (Table 2).

Vegetable-rich meals were ordered by 356 respondents out of 6301 visitors (5.7\%) during the control period and 456 out of 6650 visitors (6.9\%) during the intervention period (Table 3). Compared to the control period, during the intervention period, the visitors at the participating restaurants were younger, were female, were likely to have a history of serious medical conditions, were nonAdachi Ward residents, were university/college graduates, were regular employees, had lower average lunch expenditures, were likely to visit with others (not mainly for a meal), and were less interested in eating vegetables (Table 3).

When adjusting for all covariates, including restaurant dummy codes, compared with the control period, vegetable-rich meal orders among higher educated patrons decreased by 2.8 percentage points ( $95 \%$ CI: -3.31 to -2.37 ) during the intervention period, while the decrease was only 0.3 percentage points ( $95 \% \mathrm{CI}:-0.59$ to $0.04)$ among those with a high school education or less $(P$ for interaction $=0.041)$. Among vocational/technical school graduates, the proportion increased by 3.9 percentage points ( $95 \%$ CI: 3.06 to $4.63, P$ for interaction < 0.001; Fig. 1a). For these vocational/technical school graduates, individuals who tended to show an increase in their proportion of vegetable-rich meal orders were more likely to be over the age of 65 , female, irregular employees or unemployed, visiting the restaurant not mainly for the purpose of a meal, and reported cooking lunch regularly (data not shown).

The change in vegetable-rich meal orders (percentage points) was -1.4 among regular employees (95\% CI: 1.66 to -1.05$),+5.2$ among irregular employees $(95 \%$ CI: 4.54 to $5.76, P$ for interaction $=0.001$ ), and -11.9 among self-employed patrons ( $95 \%$ CI: -16.54 to -7.19 , $P$ for interaction $=0.013$; Fig. $1 \mathrm{~b}$ ). The change in vegetable-rich meal orders among customers who usually paid the most $(850+$ yen) to eat out for lunch was 2.1 percentage points (95\% CI: 1.66 to 2.62 ), while those who reported that they paid the least (450 yen or less) increased their vegetable-rich orders by 3.8 percentage points (95\% CI: 2.82 to $4.76, P$ for interaction $=0.001$ ). The change among those who reported spending an intermediate amount (451-850 yen) was -3.3 (95\% CI: -3.99 to $-2.65, P$ for interaction $=0.001$; Fig. $1 \mathrm{c}$ ).

\section{Discussion and conclusions}

As hypothesised, the intervention program increased the number of visitors to restaurants by 1.04 times, and among the visitors, the total proportion of vegetable-rich meal orders also increased by 1.5 times. This resulted in 
Table 1 Characteristics of participating restaurants

\begin{tabular}{|c|c|c|c|c|c|}
\hline & Weekly business & Type & Characteristics of vegetabl & neals & \\
\hline & & & Number of meals offered & Single dish or combo ${ }^{a}$ & Price (Japanese yen) \\
\hline A & 5 & Casual/family & 1 & Combo & 950 \\
\hline B & 6 & Casual/family & 1 & Combo & 1029 \\
\hline C & 7 & Izakaya pub & 1 & Single dish & 680 \\
\hline D & 6 & Chinese & 1 & Combo & 800 \\
\hline E & 6 & Italian & 1 & Combo & 1000 \\
\hline$F$ & 4 & Italian & 4 & Combo & $880,1080,1280,1450$ \\
\hline G & 5 & Cafe & 1 & Combo & 900 \\
\hline H & 6 & Udon noodle & 1 & Combo & 830 \\
\hline । & 7 & Izakaya pub & 3 & $\begin{array}{l}\text { Single dish, } \\
\text { Combo }\end{array}$ & $\begin{array}{l}680 \\
720,780\end{array}$ \\
\hline J & 6 & Italian & 1 & Combo & 880 \\
\hline K & 5 & Cafe & 2 & Combo & 880 \\
\hline L & 5 & Casual/family & 1 & Combo & 900 \\
\hline M & 6 & Western & 2 & Single dish & 480,560 \\
\hline N & 7 & Italian & 1 & Combo & 930 \\
\hline O & 6 & Japanese & 1 & Single dish & 600 \\
\hline$P$ & 6 & Izakaya pub & 1 & Single dish & 880 \\
\hline Q & 7 & Ramen noodle & 1 & Combo & 850 \\
\hline $\mathrm{R}$ & 6 & Ramen noodle & 2 & Combo & 950 \\
\hline S & 6 & Italian & 5 & Single dish & $324,432,540,756,972$ \\
\hline $\mathrm{T}$ & 6 & Chinese & 3 & Single dish & $600,1000,1000$ \\
\hline U & 7 & Izakaya pub & 1 & Single dish & 680 \\
\hline V & 6 & Cafe & 1 & Combo & 1300 \\
\hline W & 6 & Cafe & 1 & Combo & 850 \\
\hline$x$ & 6 & Casual/family & 4 & Combo & $780,780,800,880$ \\
\hline Y & 6 & Chinese & 2 & $\begin{array}{l}\text { Single dish, } \\
\text { Combo }\end{array}$ & $\begin{array}{l}700 \\
650\end{array}$ \\
\hline$Z^{b}$ & 7 & Izakaya pub & 1 & Single dish & 650 \\
\hline
\end{tabular}

The number of orders, visitors and total sales per day in each restaurant are shown in Additional file 1: Supplementary Material 3

${ }^{a}$ Single dish salad-type meal or combo-type meal

${ }^{\mathrm{b}}$ Dropped out

increased daily restaurant sales during the intervention period. The overall success of this campaign (i.e. an increase in the number of visitors to the participating restaurants and people choosing healthier meals) is consistent with recent intervention trials using positive incentives for health behaviour [18]. The intervention was most effective among the group with the lowest purchasing power, who exhibited the largest increase in their likelihood of ordering vegetable-rich meals.

The equalising impact of the intervention was most notable when analysing effect sizes based on participants' financial conditions. Our results were not consistent with those from a supermarket-based randomised controlled trial that provided financial incentives for recommended food in New Zealand. This trial revealed no difference in the effect based on customers' income and education [24]. A potential explanation for this inconsistency could be differences in the settings of each intervention (supermarkets vs restaurants). Customers at restaurants, as in the present study, usually select and consume meals for themselves, while foods purchased at supermarkets are not necessarily consumed by the purchaser. Moreover, there also exists a longer time lag between the action (taking food from the supermarket shelves) and consumption in a retail setting compared to a restaurant, in which customers eat the meal immediately after being served. Marketing research suggests that immediate and direct rewards are more effective in securing customers' loyalty (i.e. repeated purchases) [33, 34]. 
Table 2 Ratios of vegetable-rich meal orders and daily restaurant sales (during the intervention period vs the control period)

\begin{tabular}{|c|c|c|c|}
\hline & Non-adjusted & Model 1 & Model 2 \\
\hline \multicolumn{4}{|l|}{ Vegetable-rich meal orders } \\
\hline Intervention (ref. control) & $1.33(1.18,1.49)$ & $1.35(1.21,1.52)$ & $1.50(1.29,1.75)$ \\
\hline Weekends (ref. weekdays) & & & $1.18(0.98,1.42)$ \\
\hline Temperature (per $1^{\circ} \mathrm{C}$ increase) & & & $0.91(0.86,0.97)$ \\
\hline Humidity (per 10\% point increase) & & & $1.06(0.99,1.13)$ \\
\hline Weather: Rain (ref. not rain) ${ }^{a}$ & & & $0.89(0.74,1.08)$ \\
\hline Adjusted for fixed effects of restaurants & No & Yes & Yes \\
\hline \multicolumn{4}{|l|}{ Restaurant sales } \\
\hline Intervention (ref. control) & $1.14(0.63,2.05)$ & $1.15(0.82,1.61)$ & $1.77(1.11,2.83)$ \\
\hline Weekends (ref. weekdays) & & & $1.22(0.75,1.98)$ \\
\hline Temperature (per $1^{\circ} \mathrm{C}$ increase) & & & $0.81(0.69,0.96)$ \\
\hline Humidity (per 10\% point increase) & & & $0.92(0.78,1.07)$ \\
\hline Weather: Rain (ref. no rain) ${ }^{a}$ & & & $0.70(0.44,1.12)$ \\
\hline Adjusted for fixed effects of restaurants & No & Yes & Yes \\
\hline
\end{tabular}

${ }^{\mathrm{a} B a s e d}$ on weather during business hours. We estimated the ratios for vegetable-rich meal orders and restaurant sales separately. Model 1 adjusted for fixed effects of restaurants by adding the dummy variables identifying restaurants. In Model 2, we further added daily temporal and climatic data as covariates

Financial incentives could encourage people to engage in the targeted behaviour by two mechanisms. First, this type of incentive encourages people to change their considered decisions by making up the difference between the utility values for each choice. If a regular meal costs 600 yen, and a particular individual values an added vegetable serving at 100 yen, then a 100-yen cash-back campaign is sufficient for encouraging the individual to purchase the meal. Alternatively, an individual may purchase the vegetable serving, even if the discount is less than 100 yen-say, 50 yen, as in our intervention-if the time-limited cash-back offer stimulates the individual's affect (i.e. a sense of a perceived "deal", loss-aversion, or enjoyment). The latter is in line with the concept of nudging [13]. In our study, 25 out of 43 vegetable-rich meal options were more expensive than regular meals by more than 50 yen. In such cases, those who ordered the vegetable-rich meals paid extra money for those vegetables.

We should note the limitations of this study. First and foremost, although we had strong advantages with our study design as mentioned above, the non-parallel design is prone to selection bias. For example, the results of our adjusted estimates for total vegetable-rich orders and restaurant sales were, when considering the weather, day of the week, and restaurant, fixed effects that were larger than the crude estimates. This may be due to the strong confounding factors, as the intervention was implemented in the unstable rainy season. However, residual confounding is also possible. In fact, compared to the control period, during the intervention period, visitors to the participating restaurants were more likely to be young, female, university graduates, and regular employees. They were basically less likely to order vegetable-rich meals in the intervention period, potentially resulting in an underestimation of the impacts of the intervention on vegetable-rich meal orders. Meanwhile, the intervention also involved more non-Adachi residents, unemployed and poorer individuals (paying less for lunch), people visiting with someone, and people not visiting mainly for a meal. They were more likely to order vegetable-rich meals in the campaign, potentially resulting in an overestimation of the intervention effects. To confirm the findings of this study, future studies should implement a cluster randomised trial, allocating multiple restaurants to two groups simultaneously. Because a pure randomised trial would also have critical limitations (e.g. on generalisability, feasibility), both our real-world effectiveness study and future randomised efficacy study would contribute to causal inferences $[35,36]$. Second, we could not control all the behaviours of the restaurant staff members, which introduces bias to our intervention. For example, restaurant staff members may have provided cash back to those who did not order vegetablerich meals. However, we employed an intention-totreat analysis, which evaluates the effectiveness of an intervention in a conservative way. Non-involvement among eligible customers was around $20 \%$ in both the intervention and control periods, suggesting that any bias due to non-participation was trivial. Third, repeat visitors to a restaurant, who knew the cash-back incentive was available the next week, might have held back on ordering vegetable-rich meals during the control period. However, the gap in percentage points for repeated orders was only 2.8 (5.1\% during the control 
Table 3 Proportion of vegetable-rich meal orders, $n(\%)^{a}$ by individual characteristics during the intervention and control periods

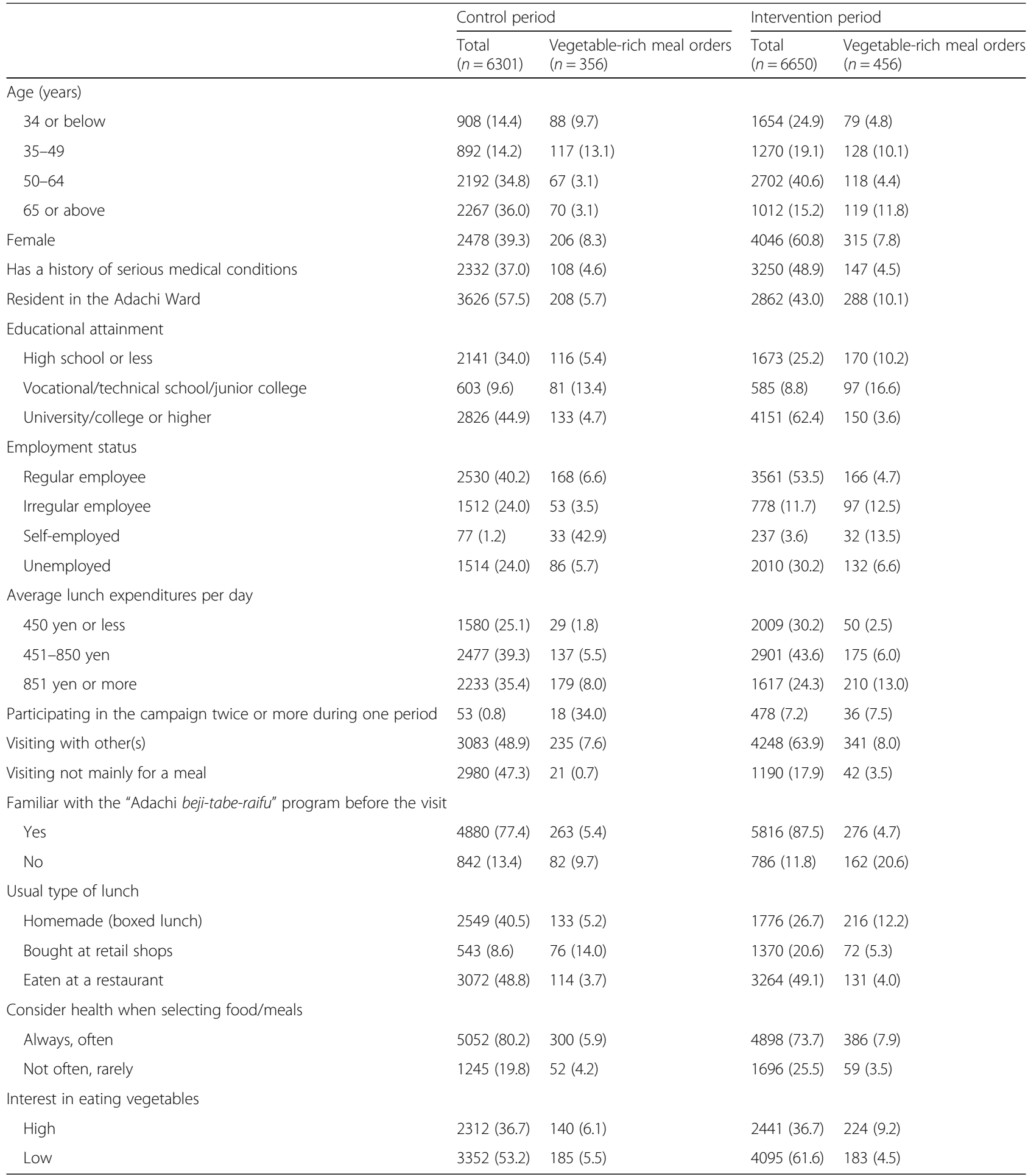

aThe percentage of "Total" column is the column percentage, and the "Vegetable-rich meal orders" column is the row percentage, respectively

period and $7.9 \%$ during the intervention period). Fourth, the actual effect size (the vegetable order gap was $2.2 \%$ ) was much smaller than the gap we assumed based on our sample size calculation (10\%), indicating that our study was underpowered. This may explain some counter-intuitive results, including the reduction in the orders of vegetable-rich meals among some subgroups in the intervention period. Given the actual effect size observed, the data required 2317 site-days based on the same statistical power and rejection rate. 


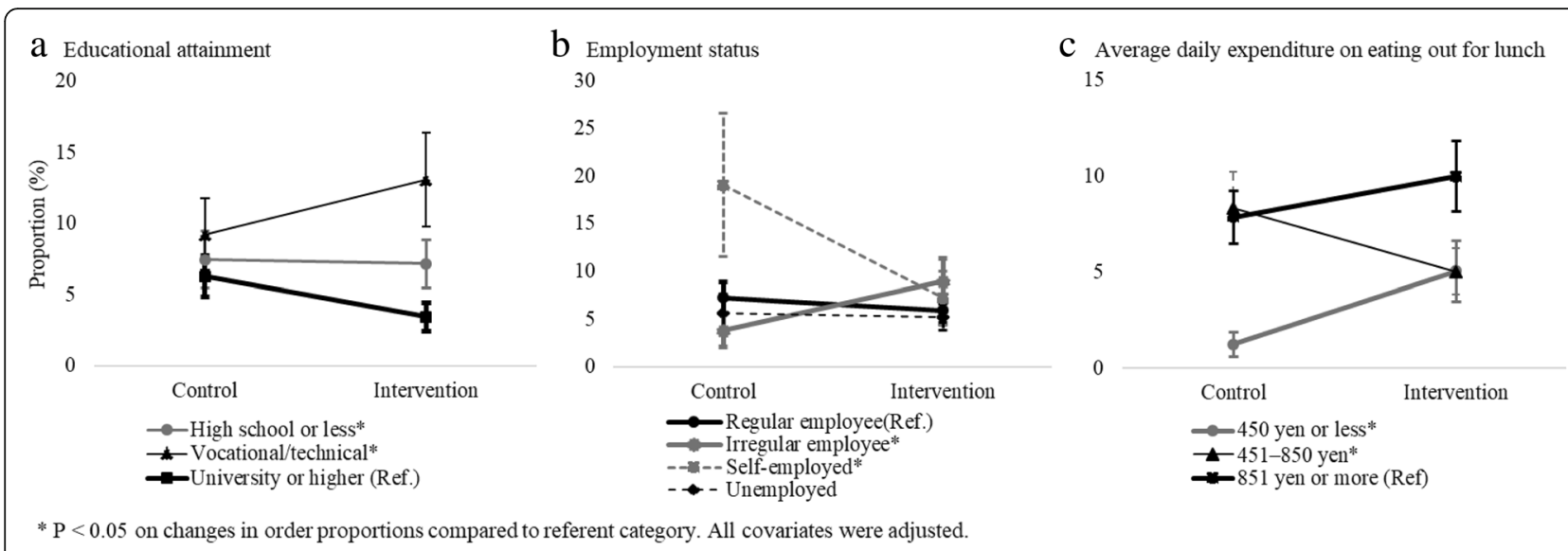

Fig. 1 Covariate-adjusted proportion of vegetable-rich meal orders. a Educational attainment. b Employment status. c Average daily expenditure on eating out for lunch

A larger-sized intervention is warranted in the future. Finally, despite the wide range of meal types among our participating restaurants, our representativeness of the full range of restaurants and types of eating-out venues is questionable. For example, our participating restaurants did not include popular fast food chains.

In conclusion, even a low-value monetary incentive offered over a limited period was able to increase the proportion of healthy meal orders across local restaurants. This type of intervention could encourage subgroups with low incomes and irregular employments to make healthy dietary choices. Although our study suggested potentially stronger impacts for more financially disadvantaged people, the proportional impact for other dimensions of SES was not very clear. Further analyses may help to better evaluate the impact on population subgroups with not just a single factor (e.g. income) but through multiple factors, using cluster analysis to identify subgroups with specific combinations of characteristics (e.g. low-income, male college students).

Since a single incentive might not be effective in the long run, future studies should aim to identify and evaluate similar low-cost behaviour-change options that could contribute to the design of more comprehensive and continuous interventions. Moreover, behavioural economics studies have suggested that chronic social stresses due to the scarcity of money or time could restrict cognitive function and discount the value of the benefits obtained in the future $[37,38]$. Given that, it is possible that socioeconomically disadvantaged people are less likely to engage in a health-maintaining behaviour (e.g. eating more vegetables) because that is an investment in a better future life. Thus, if financial incentive programmes for healthy choices are not enough to attract people enduring social stresses, such participants could drop-out of programmes early, or not participate in the programmes at all, which, in turn, could lead to a widening of long-term health inequalities. Another concern about our intervention is that financially disadvantaged people who cannot afford to eat out do not benefit from the intervention. Hence, when developing incentive intervention programmes for health behaviours, it is essential to undertake careful long-term evaluations of the programmes according to social subgroups and create necessary modifications to make the intervention programmes effective, feasible, and sustainable in reducing inequality in the targeted health behaviours [14]. Creating a knowledge base of various behavioural approaches should contribute to global strategies geared toward addressing health inequalities.

\section{Additional file}

Additional file 1: Supplementary Material 1. Frequency weights calculation. Supplementary Material 2. Additional descriptions on study design and analysis. Supplementary Material 3. The number of orders, visitors and the total takings per day in each restaurant. Supplementary Material 4. Flow diagrams of participating individuals and restaurants. (DOCX $88 \mathrm{~kb}$ )

\section{Acknowledgements}

The authors are grateful to The Adachi Word and participated restaurant owners for collaboration on the implementation of this trial. We also would like to thank the members of Department of Health and Social Behaviour, and Department of Health Education and Health Sociology, School of Public Health, The University of Tokyo for their support in the implementation of the survey.

\section{Authors' contributions}

WN was involved in the literature search, study design, data collection, management, and analysis, interpretation of the results, and drafting of the manuscript. JS participated in the literature search, study design, data collection and analysis, interpretation of the results, and drafting of the manuscript. NK proposed the initial idea and led the processes of study design, data collection and analysis, interpretation, and preparation of the manuscript. All authors have access to the raw data reported in this article and take responsibility for the integrity of the data and the accuracy of the data analysis. NK is the guarantor for this study. The corresponding author attests that all listed authors meet the authorship criteria and that no others 
meeting the criteria have been omitted. All authors of this paper have read and approved the final submitted version.

\section{Funding}

This work was supported by the Japan Society for the Promotion of Science (No. 26670306, 18H04071)

\section{Availability of data and materials}

The datasets generated and/or analysed during the current study are not publicly available due utilisation of individual data from this study is generally not permitted by the Government of Adachi Ward, but are available from the corresponding author on reasonable request.

\section{Ethics approval and consent to participate}

All procedures performed in studies involving human participants were in accordance with the ethical standards of the institutional and/or national research committee and with the 1964 Helsinki declaration and its later amendments or comparable ethical standards. The protocol was approved by The Research Ethics Committee of the Faculty of Medicine at the University of Tokyo (UMIN Clinical Trials Registry number: UMIN000022396). Informed consent was obtained from all individual participants included in the study.

\section{Consent for publication}

Not applicable.

\section{Competing interests}

We declare that the authors have no conflicts of interest with the participating local restaurants. Since the end of this intervention study, WN has received income for part-time work from the Adachi Ward Government (since 2016). The income has been received for duties not related to this study. The authors declare no other relationships or activities that could ap pear to have influenced the submitted work.

\section{Author details}

'Department of Health Education and Health Sociology, School of Public Health, The University of Tokyo, 7-3-1 Hongo, Bunkyo-ku, Tokyo 113-0033, Japan. ${ }^{2}$ Division of Prevention, Centre for Public Health Sciences, National Cancer Centre, 5-1-1 Tsukiji, Chuo-ku, Tokyo 104-0045, Japan.

\section{Received: 26 January 2019 Accepted: 6 August 2019}

\section{Published online: 12 September 2019}

\section{References}

1. World Health Organization. Noncommunicable disease fact sheet 2015. http://www.who.int/mediacentre/factsheets/fs355/en/. Accessed 8 Dec 2016.

2. Lozano R, Naghavi M, Foreman K, Lim S, Shibuya K, Aboyans V, et al. Global and regional mortality from 235 causes of death for 20 age groups in 1990 and 2010: a systematic analysis for the global burden of disease study 2010. Lancet. 2012;380:2095-128.

3. Di Cesare M, Khang YH, Asaria P, Blakely T, Cowan MJ, Farzadfar F, et al. Inequalities in non-communicable diseases and effective responses. Lancet. 2013;381:585-97.

4. Hiscock R, Bauld L, Amos A, Fidler JA, Munafo M. Socioeconomic status and smoking: a review. Ann N Y Acad Sci. 2012;1248:107-23.

5. Lynch J, Kaplan G, Salonen J. Why do poor people behave poorly? Variations in adult health behaviors and psychosoocial characteristics by stages of the socioeconomic life course. Soc Sci Med. 1997:44:809-19.

6. Darmon N, Drewnowski A. Does social class predict diet quality? Am J Clin Nutr. 2008:87:1107-17.

7. Nomura S, Sakamoto H, Glenn S, Tsugawa Y, Abe SK, Rahman MM, et al. Population health and regional variations of disease burden in Japan, 19902015: a systematic subnational analysis for the global burden of disease study 2015. Lancet. 2017;390:1521-38.

8. Ministry of Health $L$ and W. The National Health and Nutrition Survey in Japan. [In Japanese] 2014. http://www.mhlw.go.jp/stf/houdou/0000106405. html. Accessed 24 Nov 2016.

9. Fukuda Y, Nakamura K, Takano T. Accumulation of health risk behaviours is associated with lower socioeconomic status and women's urban residence: a multilevel analysis in Japan. BMC Public Health. 2005;5:53.
10. Commission on Social Determinants of Health. Closing the gap in a generation: health equity through action on the social determinants of health. Final Report of the Commission on Social Determinants of Health 2008. https://apps.who.int/iris/bitstream/handle/10665/43943/9789241563703_eng. pdf;jsessionid=1BF6DABE1205D300FAF46B6C82A84AA1? sequence=1. Accessed 3 June 2019.

11. Marmot M, Allen J, Goldblatt P, Boyce T, McNeish D, Grady M. Fair society, healthy lives: The marmot review — strategic review of health inequalities in England post-2010 2010. http://www.instituteofhealthequity.org/resourcesreports/fair-society-healthy-lives-the-marmot-review/fair-society-healthylives-full-report-pdf.pdf. Accessed 3 June 2019.

12. Benach J, Malmusi D, Yasui Y, Martínez JM. A new typology of policies to tackle health inequalities and scenarios of impact based on Rose's population approach. J Epidemiol Community Health. 2013;67:286-91.

13. Thaler RH, Sunstein CR. Nudge : improving decisions about health, wealth, and happiness. New Have: Yale University Press; 2008.

14. Glanz K, Rimer BK, Viswanath K. Health behavior: theory, research, and practice. Hoboken: Wiley; 2015

15. Michie $S$, Atkins $L$, West R. The behaviour change wheel: a guide to designing interventions. London: Silverback; 2014.

16. Nederkoorn C, Havermans RC, Giesen JCAH, Jansen A. High tax on high energy dense foods and its effects on the purchase of calories in a supermarket. An experiment. Appetite. 2011;56:760-5.

17. Colchero MA, Popkin BM, Rivera JA, Ng SW. Beverage purchases from stores in Mexico under the excise tax on sugar sweetened beverages: observational study. BMJ. 2016;352:h6704.

18. An R. Effectiveness of subsidies in promoting healthy food purchases and consumption: a review of field experiments. Public Health Nutr. 2013;16:1215-28.

19. Darmon N, Drewnowski A. Contribution of food prices and diet cost to socioeconomic disparities in diet quality and health: a systematic review and analysis. Nutr Rev. 2015;73:643-60.

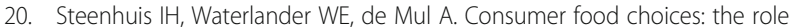
of price and pricing strategies. Public Health Nutr. 2011;14:2220-6.

21. Sassi F, Belloni A, Mirelman AJ, Suhrcke M, Thomas A, Salti N, et al. Equity impacts of price policies to promote healthy behaviours. Lancet. 2018;391: 2059-70.

22. Dallongeville J, Dauchet L, De Mouzon O, Réquillart V, Soler LG. Increasing fruit and vegetable consumption: a cost-effectiveness analysis of public policies. Eur J Pub Health. 2011;21:69-73.

23. Darmon N, Lacroix A, Muller L, Ruffieux B. Food price policies improve diet quality while increasing socioeconomic inequalities in nutrition. Int J Behav Nutr Phys Act. 2014;11:1-12.

24. Blakely T, Ni Mhurchu C, Jiang Y, Matoe L, Funaki-Tahifote M, Eyles HC, et al. Do effects of price discounts and nutrition education on food purchases vary by ethnicity, income and education? Results from a randomised, controlled trial. J Epidemiol Community Health. 2011;65:902-8.

25. Tversky A, Kahneman D. Judgement under uncertainty: heuristics and biases. Science. 1974;185:1124-31.

26. Bazzano LA. Dietary intake of fruit and vegetables and risk of diabetes mellitus and cardiovascular diseases 2005. https://www.who.int/ dietphysicalactivity/publications/f\&v_cvd_diabetes.pdf. Accessed 3 June 2019

27. Lim SS, Vos T, Flaxman AD, Danaei G, Shibuya K, Adair-Rohani H, et al. A comparative risk assessment of burden of disease and injury attributable to 67 risk factors and risk factor clusters in 21 regions, 1990-2010: a systematic analysis for the global burden of disease study 2010. Lancet. 2012;380:2224-60.

28. Nagura J, Iso H, Watanabe Y, Maruyama K, Date C, Toyoshima H, et al. Fruit, vegetable and bean intake and mortality from cardiovascular disease among Japanese men and women: the JACC study. Br J Nutr. 2009;102: 285-92.

29. Imai S, Fukui M, Kajiyama S. Effect of eating vegetables before carbohydrates on glucose excursions in patients with type 2 diabetes. J Clin Biochem Nutr. 2014:54:7-11.

30. Bank of Japan. BOJ time series data search. [In Japanese] n.d. http://www. stat-search.boj.or.jp/ssi/cgi-bin/famecgi2?cgi=\$nme_a000\&lstSelection= FM08. Accessed 11 Apr 2019

31. Japan Meteorological Agency. Kako no kisyo deta kensaku (Tokyo in June). [In Japanese] 2016. http://www.data.jma.go.jp/obd/stats/etrn/view/daily_s1. php?prec no $=44 \&$ block $\_$no $=47662 \&$ year $=2016 \&$ month $=6 \&$ day $=\& v i e w=$ Accessed 2 Dec 2016. 
32. Barros AJD, Hirakata VN. Alternatives for logistic regression in cross-sectional studies: an empirical comparison of models that directly estimate the prevalence ratio. BMC Med Res Methodol. 2003;3:21.

33. Dowling GR, Uncles M. Do customer loyalty programs really work? Sloan Manag Rev. 1997;38:71

34. Yi Y, Jeon $\mathrm{H}$. Effects of loyalty programs on value perception, program loyalty, and brand loyalty. J Acad Mark Sci. 2003;31:229-40.

35. Victora CG, Habicht J-P, Bryce J. Evidence-based public health: moving beyond randomized trials. Am J Public Health. 2004;94:400-5.

36. Frieden TR. Evidence for health decision making -beyond randomized, controlled trials. N Engl J Med. 2017:377:465-75.

37. Mani A, Mullainathan S, Shafir E, Zhao J. Poverty impedes cognitive function. Science. 2013;341:976-80

38. Mullainathan S, Shafir E. Scarcity: why having too little means so much. New York: Times Books; 2013.

\section{Publisher's Note}

Springer Nature remains neutral with regard to jurisdictional claims in published maps and institutional affiliations.

Ready to submit your research? Choose BMC and benefit from:

- fast, convenient online submission

- thorough peer review by experienced researchers in your field

- rapid publication on acceptance

- support for research data, including large and complex data types

- gold Open Access which fosters wider collaboration and increased citations

- maximum visibility for your research: over $100 \mathrm{M}$ website views per year

At BMC, research is always in progress.

Learn more biomedcentral.com/submissions 